\title{
CROSS-CULTURAL ADAPTATION OF THE INNSBRUCK HEALTH DIMENSIONS QUESTIONNAIRE FOR NEUROSURGICAL PATIENTS (IHD-NS)
}

\author{
Camila Batista dos Santos', Simone Carneiro Ahualli de Carvalho', \\ Maria Fernanda Gouveia da Silva², Daniel Fuentes ${ }^{2}$, Pedro Augusto Santana ${ }^{3}$, \\ André Beer Furlan ${ }^{3}$, Paulo Henrique Pires de Aguiar ${ }^{3}$
}

\begin{abstract}
The goal of this study was to accomplish the cross-cultural adaptation of a quality of life instrument, specific for neurosurgical patients, called Innsbruck Health Dimensions Questionnaire for Neurosurgical Patients (IHD-NS). Thirty patients participated in this study, male and female, all having been submitted to brain tumor surgery more than twelve months before, and whose ages ranged from 26 to 66 . After the process of translation/back translation and the elaboration of the Brazilian version of the instrument, the patients were assessed and reassessed within a one-month period. Statistical analyses evinced the preservation of the internal consistency, high agreement levels and highly significant intra-class correlation, allowing for the belief in the quality and reliability of the Portuguese version, named Questionário de Dimensões de Saúde para Pacientes Neurocirúrgicos de Innsbruck - DSI (NC).
\end{abstract}

KEY WORDS: quality of life, cross-cultural adaptation, neurosurgery.

\begin{abstract}
Adaptação transcultural do questionário de dimensões de saúde de Innsbruck para pacientes neurocirúrgicos - DSI (NC)

Resumo - O presente estudo teve como objetivo realizar a adaptação transcultural de um instrumento de qualidade de vida, específico para pacientes neurocirúrgicos, denominado Innsbruck Health Dimensions Questionnaire for Neurosurgical Patients (IHD-NS). Participaram deste estudo 30 pacientes, de ambos os sexos, que foram submetidos a cirurgia de tumor cerebral há mais de doze meses, com idade variando entre 26 e 66 anos. Após o processo de tradução/retro-tradução e elaboração da versão brasileira do instrumento, os pacientes foram avaliados e reavaliados após um intervalo de um mês. As análises estatísticas evidenciaram preservação da consistência interna, índices de concordância elevados e correlação intraclasse altamente significativa permitindo considerar boa a qualidade e a confiabilidade da versão em português, denominada Questionário de Dimensões de Saúde para Pacientes Neurocirúrgicos de Innsbruck - DSI (NC).
\end{abstract}

PALAVRAS-CHAVE: qualidade de vida, adaptação transcultural, neurocirurgia.

In the last decades we have observed a growing interest in quality of life (QL), to evaluate not only the effectiveness and efficiency, but also the impact of certain treatments, and the physical and psychosocial impact diseases can exercise on people. There is evidence that the expression QL appeared for the first time in the medical literature in the 1930's, and that the first steps towards this perspective were made by Karnofsky et al.', in 1948. These authors developed an assessment scale of the functional state for patients with lung cancer, which has been used so far to assess the functional state of patients with dif- ferent kinds of cancer. Since then, authors have pointed to a conceptual difficulty within the expression $\mathrm{QL}$, due to its large scope. It was even described by Campbell ${ }^{2}$ apud Awad and Voruganti et al. ${ }^{3}$, in 1976, as: "a vague and ethereal entity, something about which a lot of people talk although no one knows exactly what it is". Some interpretations seem to be strictly related to health and functionality, whereas others are based on well-being, satisfaction and happiness. Examples of these views are the definitions presented below, one by Andrews and Whitey ${ }^{4}$ apud Bowling 5 , claiming QL is "The extent to which plea-

\footnotetext{
Hospital das Clínicas, Tumor Group, Medical School at the University of São Paulo, São Paulo SP, Brazil (HCFMUSP): 'Master's Degree's student from the Neurology Department at HCFMUSP; ${ }^{2}$ Psychology Assistance HCFMUSP; ${ }^{3}$ Tumor Group, Neurology Department HCFMUSP.
}

Received 24 April 2008. Accepted 4 July 2008.

Dra. Camila Batista dos Santos - Rua Maestro Cardim 808/814 - 01323-001 São Paulo SP-Brasil. E-mail: camilabsantos@gmail.com 
sure and satisfaction are achieved"; another offered by Cleary et $\mathrm{al}^{6}$, which claims "QL concerns the various aspects of an individual's life that are affected by changes in his/her health status and which are significant to his/ her quality of life". However, when one talks about QL in the health area, it seems thorough to think about the intersection of those two concepts, i.e., engrossing aspects related to health and functionality as well as to well-being, satisfaction and happiness. Some definitions gathering those concepts may be found in the specific literature, as for example:

"QL is a state of well-being that includes the ability to carry out daily activities and the satisfaction connected with the levels of functioning and control of the disease and/or the symptoms associated with the treatment" (Gotay and Moore ${ }^{7}$ );

"QL is the subjective assessment a patient makes of different aspects of his/her life, as related to his/her health status" (Guiteras and Bayés ${ }^{8}$ ) and;

"QL is not only the level of functioning, but also the level of satisfaction related to it" (Chibnall and Tait ${ }^{9}$ ).

According to Fleck et al. ${ }^{10}$, what needs to be clarified when we talk about the assessment of QL is that the patient must be the center of this evaluation, since the goal in mind is to refer to life experiences - which involves subjective aspects - and not to living conditions. It seems pertinent to think like that, once patients enjoying the same health status may see their health and life in very different ways. Devinski and Penry" expressed it very accurately by saying that "the patient would be the only person capable of knowing how he/she feels and how his/ her disease can affect his/her vigor, self-confidence, ability to socialize or get work, as well as his/her general functioning". In the health area, the different specializations, mainly oncology, found themselves confronted with the need to evaluate the living conditions of the patients that had had their life span extended due to the treatments undergone, since, in the search for "years to add to their lives", patients often forgot "the need to add life to those years". As the years went by several instruments were developed in order to measure QL in general; nevertheless, few of them propose the assessment of neurosurgical patients' QL. Considering the lack of instruments aimed at this target population and of a broader concept of QL which would include aspects such as health, functionality, satisfaction, well-being and happiness -, the current study aimed to translate and adapt the Innsbruck Health Dimensions Questionnaire for Neurosurgical Patients (IHD-NS) instrument for the Brazilian population, and also to evaluate the quality and reliability of this version. The instrument was developed by Mohsenipour et al. ${ }^{12}$, in Austria, aiming to assess neurosurgical patients' QL. It was subdivided into six domains, bearing questions based on the categorization of incapacity as described by the World Health Organization (WHO $)^{13}$. We should point to the fact that the instrument was submitted to statistical analysis and evinced a good correlation with a golden standard instrument called Nottingham Health Profile ${ }^{14}$.

The six domains mentioned above are: communication, physical condition, the function of the autonomous nervous system, self-reliance, psychological condition and social isolation. Each one of them consists of questions that express specific concepts as described below:

- The communication domain approaches matters related to auditory, visual or speaking problems, as well as the lack of interest in the surrounding reality and the reduction of the desire to communicate with people.

- In the physical condition domain, we discuss matters that investigate the existence of epileptic crises, dizziness, lack of equilibrium, trembling, excessive tiredness, sleep disorders and weight alterations.

- The third domain, called the function of the autonomous nervous system, checks the existence of problems related to sphincter and bladder control, swallowing, loss of appetite and libido alterations.

- The domain independence consists of matters related to the acts of getting up, sitting, eating and getting dressed. It still involves questions concerning household chores, work limitations and difficulty driving.

- The domain psychological condition investigates the presence of depressive symptoms, the desire to cry, the feeling of incapacity and abandonment, the sensation that one is bothering others, satisfaction regarding life, the acceptance of or the concern with the recidivism of the disease and hope in relation to the future.

- The last domain, social isolation, consists of matters approaching the presence of family problems, the feeling of loneliness and exclusion, the sensation of being judged by others, the taking of affection, support and comfort in the family context.

This questionnaire is composed of $54 \mathrm{Yes} /$ No questions. The affirmative answers score 1 point and the negative ones score 0 , except for questions 40, 41, 50 e 51, which get 1 point for a negative answer. The scoring starts being taken into account from question 7 on, and the maximum score is 48 . The higher the score, the worse the QL. Questions 1 to 7 are qualitative; they are related to social economic conditions and to the use of medication, and, therefore, do not score any points.

\section{METHOD}

\section{Casuistry}

Thirty patients belonging to both genders ( 16 female, 14 male) and aged between 26 and 66 participated in this study. All patients recruited to participate had been submitted to surgery aimed at removing brain tumor (17 left hemisphere, 13, right) 
more than twelve months prior to the assessment and none of them presented recidive of the lesion. Data collection was carried out at the Tumor Group of the Hospital das Clinicas at the University of São Paulo's Medical School.

\section{Methodology}

Among the existing cross-cultural adaptation modalities, the Guillemin et al. ${ }^{15}$ methodology was chosen. As proposed by this methodology, the instrument was translated into Portuguese by two translators with total command of the English Language (the language in the original version of the instrument). Semantic, conceptual and cultural aspects were then taken into consideration. Afterwards, a committee of judges was gathered, made up of psychology and neurosurgery professionals with command of the instrument's theme, besides fluency in both languages. At this stage a single translated version was elaborated, presenting small adaptations in items that did not make sense when literally translated into Portuguese, and aiming at a more suitable version for the Brazilian population. As there were no items totally unrelated to our culture in the instrument, it was not necessary to make any changes other than translation. Later on, the back translations were carried out by two professionals from the area related to the instrument, both of whom were fluent in the two languages. The final version, adapted to the Brazilian population, was elaborated by the judges' committee, based on the translations and back translations.

\section{Procedure}

All the patients studied were submitted to an initial assessment and then, within a month, were called for reassessment. Aiming to avoid interpretation mistakes due to their different levels of education, instead of using the original self-applied version, two examiners applied the instrument to all patients following standardized instructions.

\section{Statistical analysis}

The levels of agreement between the two versions were evaluated by means of the Kappa coefficient for each question $^{16}$, and of the intraclass correlation coefficient (ICC) for the factors and their respective factors ${ }^{17}$. The internal consistency of the translated and adapted version was evaluated by means of the coefficient Alpha de $\mathrm{Cronbach}^{18}$, comparing the correlation coefficient in each question to its factor, and of each subfactor to its respective factor.

\section{RESULTS}

The levels of agreement in the answers between test and re-test were high. All 48 questions adding up to the IHD (NS) (48 questions) presented Kappa coefficient between moderate and almost perfect (from 0.4 to 1) (Table 4). The scale's internal consistency, including the 48 questions, as well as each question independently, revealed an almost perfect level (Tables 1 and 2). The six domains of
Table 1. Internal consistency.

\begin{tabular}{cc}
\hline \multicolumn{2}{c}{ Internal consistency } \\
\hline Cronbach's alpha & No. of items \\
0.938 & 48 \\
\hline
\end{tabular}

Table 2. Cronbach's alpha.

\begin{tabular}{cccc}
\hline Item & Cronbach's alpha & Item & Cronbach's alpha \\
\hline ihd7 & .938 & Ihd31 & .936 \\
ihd8 & .937 & ihd32 & .937 \\
ihd9 & .937 & ihd33 & .936 \\
ihd10 & .937 & ihd34 & .937 \\
ihd11 & .937 & ihd35 & .936 \\
ihd12 & .938 & ihd36 & .937 \\
ihd13 & .936 & ihd37 & .939 \\
ihd14 & .937 & ihd38 & .937 \\
ihd15 & .937 & ihd39 & .936 \\
ihd16 & .936 & ihd40 & .934 \\
ihd17 & .938 & lhd41 & .937 \\
ihd18 & .937 & ihd42 & .937 \\
ihd19 & .936 & ihd43 & .936 \\
ihd20 & .938 & ihd44 & .935 \\
ihd21 & .935 & ihd45 & .935 \\
ihd22 & .938 & ihd46 & .936 \\
ihd23 & .938 & ihd47 & .936 \\
ihd24 & .939 & ihd48 & .939 \\
ihd25 & .937 & ihd49 & .938 \\
ihd26 & .937 & ihd50 & .937 \\
ihd27 & .939 & ihd51 & .939 \\
ihd28 & .939 & ihd52 & .938 \\
ihd29 & .936 & ihd53 & .934 \\
ihd30 & .937 & ihd54 & .934 \\
\hline & & & \\
\hline
\end{tabular}

Table 3. Intra-class correlation coeficient.

\begin{tabular}{lc}
\hline \multicolumn{2}{c}{ Intra-class correlation coeficient } \\
\hline Physical condition & .915 \\
Communication & .911 \\
Function of the autonomous nervous system & .903 \\
Independence & .953 \\
Psychological condition & .951 \\
Social isolation & .846 \\
\hline
\end{tabular}

which the instrument consists show highly significant intraclass correlation (Table 3).

\section{DISCUSSION}

During the translation process, it was possible to preserve the questions of the original version, since the vocabulary used, as well as the semantic constructions, were 
Table 4. Kappa coeficient.

\begin{tabular}{|c|c|c|}
\hline \multicolumn{3}{|r|}{ Kappa coeficient } \\
\hline Agreement* & Kappa & Questions \\
\hline Superficial & $0<\mathrm{K}<0.20$ & \\
\hline Considerable & $0.20<\mathrm{K}<0.40$ & \\
\hline Moderate & $0.40<\mathrm{K}<0.60$ & $11,14,27,41,44,49,52$ \\
\hline Substantial & $0.60<\mathrm{K}<0.80$ & $9,12,15,16,17,18,20,22,26,28,30,39,42,45,47,50,54$ \\
\hline Almost perfect & $0.80<\mathrm{K}<1$ & $7,10,19,31,34,35,37,38,43,46,48,51,53$ \\
\hline Perfect & 1 & $8,13,21,23,24,25,29,32,33,36,40$ \\
\hline
\end{tabular}

part of the linguistic command of our population, and, therefore, we only needed to adapt some expressions which did not sound adequate when translated literally.

As to the administration of the test, we should point out to the importance for this instrument to be administered by an examiner, differently from the self-administration situation, since both a low educational level and the presence of cognitive changes secondary to the neurosurgical diseases might interfere with the comprehension of the questions, thus jeopardizing the reliability of the results.

The data collected from the translated and adapted version of the IHD (NS) in patients with brain tumor (right and left cerebral hemisphere) were analyzed from a statistical perspective and did not point to any random items in the essence of the instrument. Such results showed us that the answers were not variable or controversial. The translation and adaptation process preserved the original instrument's internal consistency, revealing that all 48 questions contribute to its format.

Even so, it is important to point out to the fact that the questions "I have trouble driving a car" and "I often get tired when I'm practicing sports" need to be revised in a validation procedure, since they are not applicable to individuals in all social economic levels, and therefore, may interfere with the instrument's global scoring.

The translated/adapted version reached a high general level of agreement when compared to the original version. The coefficients of intraclass correlation were highly significant to the scorings in the Portuguese version, considering all factors and sub-factors. The agreement analysis carried out by means of the Kappa coefficient revealed great statistical value.

All information points to the good quality and the reliability of the Portuguese version, which reveals good internal consistency, a high level of agreement and no random items in its format. Considering (a) the data above, (b) the need for QL instruments specific for neurosurgi- cal patients, and (c) the quality of IHD (NS) in what concerns the format, approaching aspects related to health, functionality, satisfaction, well-being and happiness, it is considered relevant to carry out the validation process of such instrument.

\section{REFERENCES}

1. Karnofsky DA, Abelmann WH, Craver LF, Burchenall JF. The use of nitrogen mustard in the palliative treatment of cancer with particular reference to bronchogenic carcinoma. Cancer 1948;1:634-656.

2. Campbell A. Subjective measures of well-being. American Psychologist 1976;31:117-124.

3. Awad G, Voruganti LNP. Intervention research in psychosis: issues related to the assessment of quality of life. Schizophr Bull 2000;26: 557-564.

4. Andrews FM, Withey SB. Social indicators of well-being. New York: Plenum Press, 1976.

5. Bowling A. What things are important in people's lives? A survey of the public's judgments to inform scales of health related quality of life. Soc Sci Med 1995;41:1447-1462.

6. Cleary PD, Wilson PD, Fowler FJ. Health-related quality of life in HIVinfected persons: a conceptual model. In Dimsdale JE, Baum A (Eds.) Quality of life in behavioral medicine research. New Jersey: Lawrence Erlbaum Associates, 1995:191-204.

7. Gotay CC, Moore TD. Assessing quality of life in head and neck cancer. Qual Life Res 1992;1:5-17.

8. Guiteras AF, Bayés R. Desarrollo de un instrumento para la medida de calidad de vida en enfermedades crónicas. In Forns M, Anguera MT (Eds.). Aportaciones recientes a la evaluación psicológica. Barcelona: Universitas, 1993:175-195.

9. Chibnall JT, Tait RC. The quality of life scale: a preliminary study with chronic pain patients. Psycol Health 1990;4:283-292.

10. Fleck MPA \& Cols. A avaliação da qualidade de vida: Guia para profissionais da saúde. Porto Alegre: Artmed, 2008.

11. Devinsky O, Penry JK. Quality of life in epilepsy: the clinician's view. Epilepsy 1993;34:4-7.

12. Mohsenipour I, Deusch E, Gabl M, Hofer M, Twerdy K. Quality of life in patients after meningeoma resection. Acta Neurochir (Wien) 2001; 143:547-553.

13. World Health Organization. International Classification of Functioning, disability and health (ICF). Geneva: WHO, 2001.

14. Hunt SM, McKenna SP, McEwen J. The Nottingham health profile: user's manual. Galen research and consultancy. Manchester, 1989.

15. Guillemin F, Bombardier C, Beaton D. Cross-cultural adaptation of health related quality of life measures: literature review and proposed guidelines. J Clin Epidemiol 1993;46:1417-1432.

16. Bartko JJ, Carpenter WTJR. On methods and theory of reliability. J Nerv Ment Dis 1976;163:307-317.

17. Bartko JJ. Measurement and reliability: statistical thinking considerations. Schizophr Bull 1991;17:483-489.

18. Cronback LJ. Coefficient alpha and the internal structure of tests. Pychometrika 1951;16:297-335. 